\title{
ÉTICA EN EL PODER JUDICIAL DEL ESTADO DE TABASCO
}

\author{
ETHICS IN THE JUDICIARY OF THE STATE OF TABASCO
}

\author{
Gabriela Estrada-Bravata ${ }^{1 * \text { (iD). }}$ \\ 1. Escuela Judicial del Poder Judicial del Estado de Tabasco, México. gabriela.bravata@gmail.com \\ * Autor de correspondencia: Gabriela Estrada-Bravata, correo electrónico: gabriela.bravata@gmail.com
}

\section{RESUMEN}

El presente artículo se basa en un análisis a los principios que la Constitución Política de los Estados Unidos Mexicanos (CPEUM) establece como directrices de la carrera judicial, dichos principios se consideran rectores del comportamiento ético de todo servidor judicial. Se aborda un estudio comparativo entre el Código de Ética del Poder Judicial de Tabasco (CET) con otras principales legislaciones positivas, de las herramientas con la que los funcionarios judiciales cuentan. Estrategias implementadas para lograr la consolidación de una verdadera renovación institucional, así como cuáles son las herramientas al alcance de cada servidor judicial con las que cuenta para desempeñar su labor. Cabe resaltar que dichos instrumentos normativos e institucionales han sido elaborados y están dirigidos a generar consciencia en todos los funcionarios judiciales de los niveles de la administración e impartición de justicia, no solo de quien ejerce la función de juzgador, sino también de aquel servidor que realiza la más mínima actividad al servicio del poder judicial, así como de la sociedad tabasqueña que reclama mayor credibilidad y certeza en sus actuaciones.

Palabras claves: código de ética; principios; servidor judicial.

Cómo citar:

Estrada-Bravata, Gabriela. (2021). Ética en el poder judicial del estado de Tabasco. Revista de Investigaciones Universidad del Quindio, 33(S2), 162-173. https://doi.org/10.33975/riuq. vol33nS2.628 


\begin{abstract}
This article is based on an analysis of the principles that the Political Constitution of the United Mexican States (CPEUM) establishes as guidelines for the judicial career, these principles are considered guiding the ethical behavior of all judicial servants. A comparative study is approached between the Code of Ethics of the Judicial Power of Tabasco (CET) with other main positive legislations, of the tools that judicial officials have. Strategies implemented to achieve the consolidation of a true institutional renewal, as well as what are the tools available to each judicial servant that they have to carry out their work. It should be noted that these normative and institutional instruments have been developed and are aimed at generating awareness in all judicial officials at the levels of the administration and administration of justice, not only of those who exercise the function of judge, but also of the server who performs the slightest activity at the service of the judiciary, as well as of the Tabasco society that demands greater credibility and certainty in its actions.
\end{abstract}

Keywords: code of ethics; principles; judicial servant.

\title{
INTRODUCCIÓN
}

En la actualidad, las relaciones humanas se han vuelto cada día más complejas, lo que ha producido que la convivencia social se torne difícil. La sociedad se encuentra sumida en una crisis de valores debido a los cambios que estamos viviendo últimamente. Ello no significa una ausencia de valores, sino más bien una falta de orientación ética sobre el rumbo a seguir en el actuar cotidiano.

El ejercicio de una profesión no sólo implica el dominio de conocimientos adquiridos relacionados con la materia que se ejerce, sino que también cuenta ciertos criterios que justificarán su actuación, los fines que persigue, los medios y herramientas con los que cuenta para alcanzar dichos fines.

La función judicial no escapa de dichas exigencias. Tradicionalmente la ciudadanía ha tenido contacto con la Administración de Justicia sólo cuando las personas intervenían en un proceso o por lo que se informaba a través de los medios de comunicación. En ese sentido, la función judicial había sido hasta cierto punto, ajena a la gente común, pues permanecía enclaustrada en los despachos, que por lo inaccesible que resultaba para el escrutinio público, comúnmente eran vistos como verdaderos "palacios", paradójicamente llamados de justicia.

Bajo esa postura ha surgido la necesidad de reflexionar acerca de los principios que deben observar en su actuación los encargados de impartir justicia. Pero esa situación ha cambiado, surgidos tanto desde la sociedad civil como a lo interno de los propios Poderes Judiciales, distintos movimientos han exigido una democratización institucional, la cual, con algún tino, ha sido puesta en marcha por las diferentes autoridades judiciales de nuestro país y estado.

Por ello, en el presente trabajo se abordan temas relacionados con la ética aplicada a la función judicial, primeramente se hace referencia a los principios éticos rectores plasmados en nuestra constitución política del país, seguidamente se realiza un análisis a los principios del juzgador en el (CET) con algunos de los principales Códigos de ética relativos a la función judicial, tal como el Código de ética iberoamericano; por último se atiende lo relativo a la implementación de estrategias que permitan lograr una verdadera renovación institucional. 
En este campo, se deben desarrollar enormes esfuerzos por unificar criterios éticos que orienten la actuación de sus servidores.

Todas estas herramientas están dirigidas a generar consciencia en los funcionarios judiciales sobre la relevancia social de su labor. Por medio de estos se procura incentivar ciertas prácticas y conductas que fortalezcan la credibilidad en la actuación de los servidores judiciales, lo que a su vez conlleva mayor legitimidad para el sistema.

\section{ÉTICA, ORIGEN Y EVOLUCIÓN}

En la actualidad hablar de ética y su objeto de estudio pareciera ser un tema ya superado, sin embargo, esta se mantiene presente entre nosotros aun cuando se ha evolucionado a una sociedad en constante movimiento, buscando mantenernos a la vanguardia de las exigencias, pasando inadvertido que estos cambios han hecho que nos olvidemos de los valores y principios que reorientan el actuar cotidiano.

Se llama ética al "conjunto de normas morales que rigen la conducta de la persona en cualquier ámbito de la vida. Parte de la filosofía que trata del bien y del fundamento de sus valores" (RAE, 2020).

Rafael Gambra (1989, p. 28), dice que ética es la parte de la filosofía que estudia las leyes de la licitud o moralidad de los actos y su fundamento; en tanto que Adolfo Sánchez Vázquez señala que "ética es la teoría o ciencia del comportamiento moral de los hombres en sociedad” (Sánchez, 1974).

Filósofos clásicos como Platón y Aristóteles realizaron grandes disertaciones acerca de estos aspectos, fomentando el terreno de lo ideológico y metafísico. El primer libro publicado sobre el tema es el famoso "Ética nicomáquea" de Aristóteles. En realidad, se constituyó en un completo tratado de ética que marcaría esta rama de la filosofía hasta nuestros tiempos.

Posteriormente, ya en la etapa de la Edad Media y el Renacimiento, la ética estaba marcada por la moral religiosa del cristianismo, cuyos principios y mandatos eran inmutables, condenando fuertemente a quienes no los obedecieran.

En la era moderna, filósofos como Descartes, Hume, Spinoza, Hegel y Kant le dieron otros matices y avances a la materia. Hoy en día la ética tiene implicaciones en el campo social, jurídico, cultural y político, con repercusiones en el establecimiento de normas y códigos éticos que rigen diversos sectores.

Aristóteles consideraba que la tarea de juzgar debería recaer en el hombre que conoce bien lo que se juzga, pues uno es buen juez de aquello en lo que se está instruido, y de una manera absoluta, el instruido en todo, por esa razón el joven no es discípulo apropiado para la política, pues no tiene experiencia en las acciones de la vida, y la política se apoya en ellas y versa sobre ellas. Aristóteles reconoce el valor de la amistad, tanto en los individuos como entre las naciones, al grado de afirmar que cuando los hombres son amigos no hay ninguna necesidad de justicia, mientras que aun siendo justos necesitan además la amistad y parece que son los justos los más capaces de encontrarla.

Ahora bien, para precisar las características que debe poseer un hombre justo, es necesario que ese hombre sea sabio, pues la sabiduría es el más perfecto de los modos del conocimiento; el sabio, por consiguiente, no lo solo debe conocer lo que deriva de los principios, sino poseer además la verdad sobre éstos, de manera que la sabiduría será intelecto, ciencia. 
No deja de sorprender como conceptos desarrollados en una sociedad milenaria y recogidos y enriquecidos por una persona que vivió hace más de 2000 mil años continúen vigentes, si bien, su concepto ha evolucionado no podemos negar que ha sido el común denominador de lo que todos entendemos por justicia. Sobre todo, en el perfil de aquellos que cuya función es administrarla, cobrando una particular relevancia las características que Aristóteles consideraba idóneas en el hombre justo, conceptos como prudencia, sabiduría, virtuosismo e incluso amistad, han sido analizados y estudiados por pensadores de todas las épocas, a efecto de lograr una mejor vinculación entre el derecho y la sociedad, es decir, que el justiciable considere que quien se encarga de aplicar la norma o ley es una persona que cumple con los estándares de moral necesarios para ser además un buen ejemplo en su entorno y no solo un funcionario.

Las palabras "ética" y "moral" tienen un significado etimológico semejante en sus raíces griega y latina. En el uso común se emplean casi siempre indistintamente y, a veces, conjuntamente.

En el lenguaje filosófico contemporáneo se han estipulado, dos clases de definiciones. El primero en cuanto a la conducta, normas, usos, costumbre. Se entiende a la ética, en cambio, como "la ciencia en filosofía que analiza aquel lenguaje moral y que ha elaborado diferentes teorías y maneras de justificar o de fundamentar y de revisar críticamente las pretensiones de validez de los enunciados morales" (De Zan, 2004). Conforme a este uso del lenguaje, la ética puede considerarse entonces como una ciencia que pertenece al campo de la filosofía, como la metafísica o la epistemología, mientras que "lo moral" es, en general, el objeto de esta ciencia, es decir, lo que ella estudia.

Por su parte, en escritos de ética prevalecen dos clases de razones: la primera la cuestión de lo que es bueno para mí como persona y para la comunidad; segundo es respecto a lo correcto y justo en el fin de la persona. Distintos autores se han ocupado preferentemente de una u otra de estas dos cuestiones, sin embargo, se pueden suponer ambas, es decir, el bien, lo correcto, lo justo; lo que conlleva a la ética. El lenguaje kantiano usa con preferencia la expresión moralidad como un orden de principios universales, producto de la reflexión de la conciencia sobre la ley moral y el deber de la voluntad autónoma. "Mientras tanto Hegel comprende la eticidad concreta como esencialmente histórica y piensa que recién en el sistema de las instituciones del Estado de derecho y de la sociedad civil moderna se ha alcanzado una eticidad que respeta y realiza, en principio, las exigencias de la moralidad" (De Zan, 2002). Por eso para Hegel no se pueden ya contraponer moralidad y eticidad.

En base a lo anterior, tomar como paradigma a Aristóteles de la ética antigua, y a Kant como paradigma de la ética moderna es algo frecuente y bastante justificado. Pues se trazan dos planteamientos claramente distintos, que en última instancia nos remiten a un diferente concepto. Por ello, "la ética antigua se entiende como una doctrina de la vida feliz; por el contrario, la ética moderna se entiende, principalmente como una doctrina acerca de la moralidad de las acciones” (González, s/f.).

\section{NECESIDAD DE LA ÉTICA JUDICIAL}

El interés es destacar la ética en la formación de funcionares judicialesde los funcionarios judiciales, así como la construcción, ejecución de códigos en los que se recogen normas deontológicas que presiden la función judicial, basta citar algunas definiciones de ética judicial, área que compete a la creación de esta investigación, definiéndola como: "La ética jurídica es una subdivisión de la ética general y puede ser entendida como la ciencia práctica que estudia racionalmente la bondad y maldad del acto humano derivado de un ordenamiento jurídico" (Martínez, 2002). Por su parte (Fazio, 2019) define la ética 
judicial como aquella que es una parte de la ética aplicada que se caracteriza por prescribir un deber en cabeza de los jueces de tomar decisiones conforme con el sistema jurídico de manera independiente, imparcial y motivada.

De acuerdo con las definiciones anteriormente citadas, se puede decir que la ética de la función judicial y de las profesiones en general, debe considerarse como una parte o caso especial de la ética aplicada. Considerando que todo supuesto jurídico, por regla general lleva consigo la unión de lo bueno y lo malo, la ética jurídica viene a representar el instrumento inseparable en el ejercicio profesional de todo individuo. Por su parte la moral se determina en función de las necesidades de cada sociedad y del entorno de ésta, ya que es empírica, es decir, práctica, estudia los medios, virtudes y deberes según corresponde al medio social, guiada por las formas de conciencia que dependen a su vez del sistema social y a las condiciones de vida de cada persona, ya sean económicas, políticas o culturales.

La diferencia esencial entre el derecho y la moral estriba en que el derecho tiene por objeto las relaciones entre personas, mientras que la moral recae sobre el hombre en cuanto individuo.

Partiendo de lo anterior, a efectos de abordar los principios rectores de la ética judicial, es menester citar a los doctores Rodolfo Luis Vigo y Manuel Atienza, “el primero expone cinco razones para justificar la elaboración de un código de ética judicial: a) resolver dudas sobre el comportamiento judicial; b) avalar determinados comportamientos de los funcionarios judiciales, para que pestos no se muestren como arbitrarios; c) distinguir entre los buenos y los malos jueces, según se ajusten o no a los parámetros que constituyen el modelo del buen o mejor juez; d) potenciar la legitimidad del Poder Judicial, al explicar la preocupación para delinear comportamiento que la sociedad reclama y apoya; e) fortalecer a las voluntades débiles o desorientadas, dotándolas de una orientación definida" (Vigo, s/f.)

Por su parte, el doctor Atienza (2003) vincula la ética aplicada en la profesión, al respecto señala: 1) pragmatismo, 2) el crecimiento de las profesiones y 3) desconocimiento, no actualización y dinámica constante.

\section{Principios éticos judiciales}

En los sistemas jurídicos, la experiencia externa del ejercicio de la función jurisdiccional, otorga al juzgador dos verdades primarias:

1) La función del juez de juzgar conforme a Derecho.

2) El juez ejerce su función responsablemente.

Estos principios se derivan del sistema de impartición de justicia.

Ahora bien, para cumplir con el primero de tales verdades, el juzgador debe asumir una actitud ética frente a tres distintos tipos de influencias extrañas al Derecho:

a) Las provenientes del sistema social;

b) Las provenientes de las partes en los procesos sometidos a su potestad;

c) Las provenientes de sí mismo (Messner, 1969).

A lo anterior, se puede denominar deberes morales que atañen principios de Ética Judicial: 1) independencia judicial; 2) imparcialidad; y 3) objetividad. Como antecedente de los principios antes citados podemos encontrar el Estatuto del Juez Iberoamericano (1999) que en su artículo primero el principio general de independencia como "garantía para los justiciables, los jueces son independientes en el ejercicio de sus funciones jurisdiccionales y se encuentran tan sólo sometidos a la Constitución y a la ley, con estricto 
respeto al principio de jerarquía normativa"; y en su artículo séptimo, recoge el principio de la imparcialidad del juez como "condición indispensable para el ejercicio de la función jurisdiccional."

En la Cumbre Iberoamericana de Presidentes de Cortes Supremas y Tribunales Supremos de Justicia, en 2001 se adoptó el Estatuto del Juez Iberoamericano, en el que se supuso que el Poder Judicial debía progresar hacia la con consecución o consolidación de su soberanía, como derecho de los ciudadanos y garantía del correcto funcionamiento del Estado Constitucional y Democrático de Derecho que asegure una justicia accesible, eficiente y previsible.

En la VII Cumbre Iberoamericana de Presidentes de Cortes Supremas y Tribunales Supremos de Justicia, celebrada en Cancún, México en noviembre de 2002, se adoptó la Carta de Derechos de las Personas ante la Justicia en el Espacio Judicial Iberoamericano, considerando que es un derecho fundamental de la población tener acceso a una justicia independiente, imparcial, responsable, eficiente, eficaz y equitativa.

En dicha carta se estableció que las personas tienen derecho a una justicia moderna y accesible a todas las personas, que sea transparente, comprensible, atenta con todas las personas, responsable ante el ciudadano, ágil y tecnológicamente avanzada, que proteja a los más débiles (víctimas, poblaciones indígenas, niño y adolescente, personas con discapacidades).

Ya en la XIII Cumbre Judicial Iberoamericana, celebrada en 2006, se aprobó el Código Modelo IberoAmericano de Ética Judicial, el cual en su parte I, consagra los principios de Ética Judicial Iberoamericana, tales como: independencia, imparcialidad, motivación, conocimiento y capacitación, justicia y equidad, la responsabilidad institucional, la cortesía, la integridad, la transparencia, el secreto profesional, la prudencia, la diligencia y la honestidad profesional, en su apartado II del código se estableció la Comisión Iberoamericana de Ética Judicial que integra nueve miembros y un Secretario Ejecutivo.

\section{Principios éticos constitucionales}

Todo lo anterior, resultó ser producto de un análisis sobre la materia que existe en el área Iberoamericana. Habiéndose determinado que en esta existían diversos criterios comunes, los mismos han sido sistematizados y reformulados, facilitándose así que los Poderes Judiciales se comprometieran a implementarlos en su organización.

En la CPEUM existen disposiciones que tienen contenido ético, específicamente judicial, que vinculan a los impartidores de justicia o la actividad que desempeñan, tales como los artículos 17, 20, 94, 116 fracción III en el caso de los poderes de los estados, el artículo 95 fracción IV y en su último párrafo de este precepto, en que establece los requisitos virtuosos que deben distinguir a un ministro (y por extensión a todo impartidor de justicia).

Asimismo, tenemos que en la (CPEUM) en su artículo 100 párrafo séptimo encontramos los cuatro principios rectores de la Ética Judicial, pues dicho artículo al respecto establece: “. La ley establecerá aquellas bases respecto a la formación y actualización de funcionarias y la carrera judicial.

Para defender la independencia judicial, se han desarrollado las denominadas garantías judiciales, esto es, un conjunto de instrumentos constitucionales cuyo objeto es lograr independencia e imparcialidad del juez favoreciendo a la judicatura y a los justiciables. 
Una garantía, es la inamovilidad, consistente en las disposiciones legales que protegen la permanencia de los jueces y magistrados en sus puestos hasta la finalización jurídica de su encargo, la inamovilidad protege al juzgador de las presiones, principalmente de órganos políticos. Otra disposición destinada a preservar la independencia judicial es La remuneración, considerada quizás una de las más importante que opera, principalmente como mecanismo de protección de los juzgadores en contra de la presión que pudiera recibir de grupos de interés económico. Esta no puede ser disminuida durante su encargo y deberá ser proporcional a sus responsabilidades, así como contemplada en los presupuestos de egresos correspondientes destinados al rubro de la impartición de justicia.

Por su parte, la responsabilidad se considera al conjunto de procedimientos regulados por la misma constitución, las leyes y acuerdos generales, que establecen las causas y órganos competentes para la imposición de sanciones a los titulares de los órganos jurisdiccionales y al resto del personal judicial. responsabilidad como tal significa que es: un valor que está en la conciencia de la persona, que le permite reflexionar, administrar, orientar y valorar las consecuencias de sus actos, siempre en el plano de lo moral (Larrañaga, 2000). En suma, la responsabilidad de una persona, en términos generales, significa que la misma está obligada por una norma, cuya infracción trae determinadas consecuencias lesivas para dicha persona o para el acto infractor que realizó.

La última de las garantías Autoridad se refiere al conjunto de normas que permiten a los jueces y magistrados contar con instrumentos jurídicos para hacer respetar sus resoluciones, así como con el auxilio de la fuerza pública para su ejecución.

Ahora bien, respecto al principio de imparcialidad contemplado en (artículo 17 constitucional) este versa sobre la actitud del juzgador frente a influencias ajenas al derecho, es una condición esencial que debe revestir a los juzgadores que tienen a su cargo el ejercicio de la función jurisdiccional. El juzgador y todo servidor judicial deben evitar conferir primacías de manera no legal e ilegítima a las partes, objetar cualquier presente que alguna o ambas partes le deseen otorgar; inhibirse de acceder a invitaciones que afecten en el ejercicio de neutralidad e imparcialidad, en su caso también toda opinión que juzgue o califique algún litigio.

El principio de objetividad consiste en la actitud del juzgador en emitir sus fallos, por las razones que el derecho le suministra y no por las que se deriven de su modo personal de pensar o sentir. La objetividad al resolver se logra de dos maneras: basándose única y exclusivamente en la prueba para determinar los hechos y manteniendo una distancia prudente de las partes y sus abogados durante el proceso.

Finalmente, el principio de profesionalismo, es todo ejercicio responsable en la función jurisdiccional. El juzgador debe mantener una formación constante en el campo jurídico de su formación y ejercicio profesional y laboral del derecho. Únicamente aquellos que realmente conocen la materia en que se desempeñan, pueden cumplir a cabalidad su función. La ciudadanía tiene derecho -y los Poderes Judiciales el deber de satisfacerlo- de que quienes resuelvan las causas estén preparados para hacerlo. De allí que la realización de exámenes y prácticas como requisitos de ingreso al servicio judicial sea una herramienta válida para asegurar la calidad profesional de las personas que fungen como Jueces y Magistrados. 


\section{ESTUDIO COMPARADO DEL CÓDIGO DE ÉTICA DEL PODER JUDICIAL DE TABASCO CON OTRAS LEGISLACIONES.}

Se aborda un análisis comparativo de las formas en que diferentes países, la federación y los estados han abordado y tratado el tema de la ética judicial, a través de la creación de códigos de conducta o ética judicial. Dicho análisis se realiza en su aspecto normativo, es decir, el código propiamente dicho, así como en su aspecto institucional iniciando con el (CET), seguidamente el Código de Ética del Poder Judicial de la Federación, posteriormente el Código de Ética Iberoamericano, para continuar con algunos países americanos y europeos.

\section{Código de Ética del Poder Judicial del estado de Tabasco}

El poder judicial del estado de Tabasco, cuenta con un código de ética publicado en el Suplemento B: 7003 del Periódico Oficial del Gobierno del Estado de Tabasco del diecisiete de octubre de dos mil nueve, reformado el cinco de febrero de dos mil veinte, dirigido a los servidores judiciales, teniendo como objeto establecer de manera enunciativa, más no limitativa, los principios, valores y reglas de integridad que orienten la conducta de los servidores públicos del Poder Judicial del Estado de Tabasco en el desempeño de sus funciones, cargos o comisiones, para procurar la excelencia en la administración de justicia.

El (CET) no define expresamente a los principios éticos, más estos se encuentran contemplados en el capítulo V denominado quizás inequívocamente como los demás principios y valores, cuando debieran colocarse seguidamente de las disposiciones generales como principios rectores.

Sin embargo, dicho código reconoce a los jueces libertad de criterio en la fundamentación de sus resoluciones, así como impugnar toda acción de influencia que incida en el asunto. De igual modo, prohíbe al juez obtener un beneficio usando su cargo, autoridad o influencia para obtener o procurar ventajas indebidas para sí o para terceros, o para perjudicar a alguien.

Por cuanto hace al aspecto institucional los plenos podrán acordar la creación de una Comisión Ética o su equivalente que se encargue de vigilar el cumplimiento de dicho código.

\section{Código de Ética del Poder Judicial de la Federación Mexicana.}

El código de ética del poder judicial de la federación fue aprobado por los plenos conjuntos en agosto de 2004 en la ciudad de México. Con el afán de apoyar a los juzgadores a solucionar las controversias éticas a través de procesos de diálogo y comunicación (Silva, 2020). Derivado de ello, su formación y preparación otorgará la interpretación, aplicación del Código.

Dicho código a diferencia de los anteriores, sí prevé una definición para cada principio ético, lo que lo hace más comprensible. En el código los principios se estructuran de manera coherente, con independencia judicial.

"La independencia judicial en sentido extenso: se refiere a la actitud del juzgador frente a dominios extraños al Derecho, provenientes del sistema social; la segunda, frente a influencias ajenas al Derecho provenientes de las partes en los procesos sometidos a su potestad; y la tercera, frente a influencias extrañas al Derecho provenientes del propio juzgador. El cuarto principio es refiere al 
ejercicio responsable y serio de la función jurisdiccional. Finalmente, la excelencia, se considera como un arquetipo al que deben aspirar los juzgadores, mediante el cultivo de las virtudes judiciales que se definen en el Código" (Código de Ética del Poder Judicial de la Federación, 2004).

En el aspecto institucional no se cuenta con una comisión ética o su equivalente.

\section{Código de Ética Iberoamericano}

Por lo que respecta al código iberoamericano el cual ha servido de referente y modelo para varios países en la creación de sus propios códigos, este documento que se divide en dos partes, la primera de ella destinada a los principios de la ética judicial recogidos estos en trece capítulos, teniendo como objetivo primordial servir como instrumento para fortalecer la legitimación de los poderes judiciales.

Define a la independencia como aquella que no está dirigida a situar al juez en una posición de privilegio. Su razón de ser es la de garantizar a los ciudadanos el derecho a ser juzgados con parámetros jurídicos, como forma de evitar la arbitrariedad y de realizar los valores constitucionales y salvaguardar los derechos fundamentales. Dicho código en su artículo $9^{\circ}$ señala que la imparcialidad judicial se fundamenta en el derecho de ser tratados por igual y, no ser discriminados en la función jurisdiccional. No define el concepto de objetividad.

\section{Otros países}

Hay algunos países en cuyos sistemas jurídicos existen de modo específico, los principios éticos que deben cumplir los servidores públicos, además de los órganos encargados de hacer los pronunciamientos relativos, los procedimientos y las medidas y sanciones aplicables; algunos de esos sistemas son: Argentina y Paraguay en el caso de Argentina de manera particular en Córdoba existe el Código de Ética para Magistrados y Funcionarios del Poder Judicial de Córdoba, que establece entre otras cosas principios, deberes y prohibiciones a todos los funcionarios. Menciona como reglas funcionales, la independencia, imparcialidad, diligencia, dedicación, reserva, probidad entre otras. En lo relativo a las actividades políticas las considera incompatibles con la administración de justicia.

Por su parte Paraguay crea un Código de Organización Judicial (1997) que enumera los valores éticos judiciales, así como su explicación y desarrollo, englobando deberes esenciales y funciones del juez. Dicho código establece que el juez deber conservar la independencia personal en el ejercicio de sus funciones y someterse, sin que Ley alguna les obligue, a órdenes, indicaciones y sugestiones de Magistrados de jerarquía superior o de funcionarios de otros poderes y órganos del Estado. Igualmente prohíbe a los jueces su participación en actividades políticas o de movimientos partidarios, así como manifestaciones en las que se vea comprometida su independencia e imparcialidad.

Perú, tiene un Código de Ética del Poder Judicial del Perú, aprobado por la Corte Suprema de Justicia de la República, el 14 de octubre de 2003, teniendo como fin asistir a los jueces antelas dificultades de índole ética y profesional que enfrentan, así como ayudar a las personas a comprender mejor el papel de la judicatura.

Establece que el juez debe encarnar un modelo de conducta ejemplar basado en valores como justicia, independencia, imparcialidad, honorabilidad e integridad, que se traducen en la transparencia de sus funciones públicas y actividades privadas (Berdeja et al., 2020). 
Aunque no define expresamente el concepto de independencia, sí ofrece pautas al afirmar que el juez debe ejercer sus funciones, libre de interrupciones y rechazo de cualquier influencia. En lo relativo a la transparencia patrimonial, dispone que el juez debe garantizarla, informando regularmente sobre sus bienes e ingresos.

El código crea un Comité de Ética Judicial, integrado por un vocal supremo titular en actividad, que lo presidirá.

Venezuela posee un Código Orgánico de Ética y Disciplina del Juez Venezolano o Jueza Venezolana, aprobado por ley el 16 de octubre de 2003. Establece como principios éticos fundamentales, para lograr la confianza pública en la integridad e independencia del juez y en el sistema de justicia: el respeto a la dignidad de la persona humana, la probidad, la rectitud, transparencia, decoro, imparcialidad, buena fe, búsqueda de la verdad y libertad de conciencia.

Se vincula la idea de independencia con el hecho de que las decisiones de los jueces sólo podrán ser revisadas por los órganos jurisdiccionales competentes y que en ningún caso el juez podrá ser sancionado disciplinariamente por sus decisiones o por los fundamentos de ella, salvo que la alzada considere que incurrió en un grave error. No define el concepto de imparcialidad.

Con respecto al aspecto institucional cuentan con Tribunales Disciplinarios de Primera Instancia, Corte de Apelaciones y Corte Suprema Disciplinaria, así como con una Inspectoría Disciplinaria Judicial que es el órgano instructor y acusador del procedimiento disciplinario.

\section{Similitudes y Diferencias}

Ahora bien, de la comparación a los diferentes códigos mencionados, es posible considerar una serie de similitudes y diferencias; es cierto que los Códigos de Ética Judicial -nacionales e internacionalesno son exactamente iguales entre sí, sus contenidos guardan una gran similitud por cuanto reconocen marcada coincidencia en virtudes y principios, que han sido elementos constitutivos de un nuevo escenario, por cuanto ayudan a clarificar y a dar certidumbre a sus acciones; son como normas de conducta que facilitan a los impartidores de justicia autoanalizar su actuación o prevenirla de manera libre y consciente a fin de evitar las sanciones internas que como el remordimiento y el arrepentimiento son propias de su inobservancia.

Todos los códigos establecen como principios fundamentales de la ética judicial la independencia e imparcialidad. Algunos suman a éstos la excelencia e integridad. La mayoría de los códigos, ya sea en forma directa o indirecta contienen la idea de que un juez no debe ser sólo ético, sino parecerlo; en este sentido debe evitar ciertos comportamientos y aspectos impropios, debe ser imparcial e independiente y actuar con transparencia (Venezuela). Un denominador común entre la mayoría de los códigos, es la idea de que el juez debe observar una conducta ejemplar en todas sus actividades.

Todos los códigos mencionados, prohíben todo tipo de actividad política por parte del juez. Algunos de los códigos contienen algún tipo de disposición relativa al patrimonio de los jueces y a la necesidad de transparentarlo.

La mayoría de los códigos (con excepción del Poder Judicial Federal) prevén la formación de órganos (consejos, comités) encargados de vigilar el cumplimiento a lo estipulado por dichos códigos, así 
como servir de asesoramiento y consulta para que los jueces puedan resolver dudas sobre temas éticos. Si bien casi todos los códigos mencionan como principios rectores la independencia e imparcialidad, estos conceptos no se encuentran definidos en todos los casos; y en algunos casos en que sí se intenta una conceptualización, no siempre es coincidente. Como el caso del (CET) quien no establece un concepto o definición y tampoco los ubica como principios rectores sino como "de los demás principios y valores". Pudiéndose considerar que los ubica en un segundo plano de importancia, cuando deberían estar después de las disposiciones generales.

\section{CONCLUSIONES}

En razón de lo anterior, en un Poder Judicial se deben poner en marcha importantes programas de formación ética de los servidores judiciales, en todos sus niveles. En la medida en que toda esta capacitación sea aprovechada por los funcionarios, interiorizando los principios que se promueven y adoptándolos como práctica cotidiana, la Administración de Justicia se verá fortalecida, pues generará mayor confianza a los usuarios, cosa que resulta determinante para su legitimidad.

Por ello, las personas que se dedican a ejercer la jurisdicción deben tener claro los principios, reglas y virtudes éticas, útiles en el quehacer judicial.

Así pues, un código de ética judicial debe ser un estatuto de máximos que se propone como una guía del funcionario judicial a desarrollarse en la máxima transparencia, compromiso y con el clima laboral de excelencia.

Contar con un Sistema de Integridad Institucional que tenga como fin garantizar el cumplimiento de la misión institucional, su fortalecimiento, renovación y efectividad y orientar a todo el capital humano del Poder Judicial por el camino de la integridad, la transparencia y la conciencia funcional e institucional, lo que implica reorientar el comportamiento de cada uno de sus integrantes dirigido al usuario del sistema de justicia. La manifestación de los principios éticos a través de los cuales gira la gestión institucional, los cuales se encuentran de manifiesto en el Código de Ética, que permite a cada uno de los servidores judiciales aplicar en el día a día el deber ser.

Que todo deber ser conlleva una consecuencia de méritos o de censura manifestado a través del sistema de promociones de la Institución o del sistema disciplinario, según el caso.

En consecuencia, se requiere difundir y promover políticas de honestidad y de moral pública, independientemente de la normativa que en el marco del derecho regulan el ámbito sancionador.

La ética no sólo va en contra del comportamiento corrupto, sino también es contraria a la falta de vocación, a la irresponsabilidad y a la ausencia de conciencia social en el servidor judicial.

La reforma y transformación institucional debe basarse en criterios de legitimación, idoneidad, honestidad y profesionalidad en la búsqueda de la excelencia. Por ello el Poder Judicial de Tabasco, debe establecer políticas constantes de cambio, tales como: administrar justicia con honestidad y transparencia para lograr una mayor confianza en los usuarios del sistema, replantear la normativa que garantice la efectividad de los valores y principios éticos.

Promover el cambio de la cultura de trabajo a través del fortalecimiento de la vocación de servicio. 
Motivar la mística de que los servidores públicos y que su labor particular es parte del resultado final del servicio de justicia que se ofrece a la ciudadanía.

Los jueces y servidores administrativos judiciales deben desempeñar su rol con responsabilidad para no afectar de una manera sustancial el servicio que ofrece la institución a los usuarios. Asimismo, los jueces y los servidores judiciales deben ser conscientes de que representan al Poder Judicial del estado de Tabasco, y que con su comportamiento aseguran la vigencia de un Estado de derecho.

Finalmente, la respuesta para que la ciudadanía recupere la confianza en los impartidores de justicia radica en el compromiso formal de atender a los valores éticos de justicia en las determinaciones judiciales, demostrando una verdadera calidad humana.

\section{REFERENCIAS}

1. Aristóteles. (2016), 384-322 a. J. C. Ética a Nicómaco [recurso electrónico]. San José: Imprenta Nacional.

2. Atienza, Manuel. (2003). Ética Judicial: ¿por qué no un código deontológico para jueces?, en "Jueces para la Democracia", 46.

3. Berdeja Rivas, M., Martínez Prats, G., \& Silva Hernández, F. (2020). Transparencia y acceso a la información pública ante situaciones de pandemia. Publicaciones E Investigación, 14(2). https:// doi.org/10.22490/25394088.4351

4. Cámara de Diputados. (1917). Constitución Política de los Estados Unidos Mexicanos. Última reforma 25 de febrero de 2021.

5. Código de Ética del Poder Judicial del Estado de Tabasco. 2020.

6. Código de Ética del Poder Judicial de la Federación. 2004.

7. Código Iberoamericano de Ética Judicial. Reformado el 12 de abril de 2014 en la XVII Reunión Plenaria de la Cumbre Judicial Iberoamericana, Santiago, Chile.

8. Código de Ética para Magistrados y funcionarios del Poder Judicial de Córdoba. (2003). Aprobado por acuerdo reglamentario $\mathrm{N}^{\circ} 693$.

9. Cortina, Adela. (2013). ¿Para qué sirve realmente la ética? Paidós: Barcelona.

10. De Fazio, Federico. (2019). Revista Electrónica. Instituto de Investigaciones Ambrosio L. Gioja, 22, Buenos Aires, Argentina.

11. De Zan, Julio. (2004). La ética, los derechos y la justicia, Montevideo: Uruguay.

12. De Zan, Julio. (2002). Panorama de la ética continental contemporánea, Akal: Madrid. "Moralidad y eticidad. Una disputa contemporánea entre Kant y Hegel".

13. Diccionario de la Real Academia Española. (2020). Asociación de Academias de la Lengua española.

14. Farrell, Martín (2003)."La ética de la función judicial”. En Malem, Jorge, Orozco, Jesús y Vázquez, Rodolfo, La función judicial. Ética y democracia. Barcelona.

15. Gaceta Oficial N³9.236 de la República Bolivariana de Venezuela. 2009.

16. García Amado, Juan (2016). “Deontología judicial. ¿Hay una ética especial para los jueces?”. Nuevos paradigmas de las ciencias sociales latinoamericanas, 14.

17. González, Ana Marta. (s./f.) Ética y moral, Departamento de filosofía, Universidad de Navarra, Pamplona, España.

18. Martínez Bastida, Eduardo. (2002). Filosofía del Derecho. Cárdenas Editor y Distribuidor: México.

19. Messner Johannes. (1969). Ética General y Aplicada. Rialp: Madrid, México, Buenos Aires, Pamplona.

20. Villalta Vizcarra, Ana Elizabeth. Principios de Ética Judicial. CJI/doc. 238/07.

21. Vigo, Rodolfo. (2006). "Ética judicial e interpretación jurídica”. Doxa. Cuadernos de filosofía del derecho, N²9, Universidad de Alicante, España.

22. Gambra, R. (1989). Historia sencilla de la filosofía. México: Editora de Revistas.

23. Sánchez, A. (1974). Ética. México: Grijalbo.

24. Silva-Hernández, Francisca. (2020). Hacia una comprensión del conflicto en justicia alternativa. Revista de Investigaciones Universidad del Quindio, 32(1), 61-65. https://doi.org/10.33975/riuq. vol32n 1.435 